\title{
ALAIN QUELLA-VILLÉGER, Voyages en exotismes. Ailleurs, histoire et littérature (XIX ${ }^{e}-\mathrm{XX}^{e}$ siècles)
}

\section{Monia Mezzetti}

\section{OpenEdition}

\section{Journals}

\section{Edizione digitale}

URL: https://journals.openedition.org/studifrancesi/12167

DOI: 10.4000/studifrancesi. 12167

ISSN: 2421-5856

\section{Editore}

Rosenberg \& Sellier

\section{Edizione cartacea}

Data di pubblicazione: 1 avril 2018

Paginazione: 170-171

ISSN: 0039-2944

\section{Notizia bibliografica digitale}

Monia Mezzetti, "ALAIN QUelLa-VILlÉGer, Voyages en exotismes. Ailleurs, histoire et littérature $\left(x i x^{e}-x x^{e}\right.$ siècles)», Studi Francesi [Online], 184 (LXII | I) | 2018, online dal 03 juillet 2018, consultato il 18 novembre 2021. URL: http://journals.openedition.org/studifrancesi/12167 ; DOI: https://doi.org/ 10.4000/studifrancesi.12167

Questo documento è stato generato automaticamente il 18 novembre 2021.

\section{(†) $९$

Studi Francesi è distribuita con Licenza Creative Commons Attribuzione - Non commerciale - Non opere derivate 4.0 Internazionale. 


\title{
ALAIN QUELLA-VILLÉGER, Voyages en exotismes. Ailleurs, histoire et littérature (XIX ${ }^{e}-\mathrm{XX}^{e}$ siècles)
}

\author{
Monia Mezzetti
}

\section{NOTIZIA}

ALAIN QUELLA-VILLÉGER, Voyages en exotismes. Ailleurs, histoire et littérature (XIXe-XXe siècles), Paris, Classiques Garnier, 2017, 428 pp.

1 Il volume offre, attraverso i contributi dell'Autore, un'ampia panoramica su una letteratura difficilmente inquadrabile attraverso un'unica etichetta e che, nel corso degli ultimi cento anni, è stata detta coloniale o, viceversa, in francese, exotique. La difficoltà semantica a identificare la narrativa in oggetto non si pone soltanto in relazione al corrispettivo traduttivo nella lingua italiana, ma anche in termini ermeneutici: mentre infatti l'ambientazione esotica è obiettivamente riconoscibile, l'atteggiamento degli scrittori nei confronti della realtà narrata è suscettibile di interpretazione e, pertanto, legittima l'adozione di una voce piuttosto che dell'altra. La vasta conoscenza, da parte dell'A., del corpus testuale consente di individuare le corrette coordinate di questa tassonomia altrimenti aleatoria, come paradossalmente risulta nel libro capostipite dedicato a questo dibattito, L'Exotisme - Littérature coloniale (1911) di Louis Cario e Charles Régismanset, dove l'accostamento è del tutto arbitrario. Il romanzo coloniale, dato il suo carattere epico, mette in campo il tema del coraggio e dell'eroismo, mentre, sul piano ideologico, si configura come anti-exotique in quanto promuove il primato della madrepatria, tale per cui «Les colonies ne sont pas l'étranger. Une colonie française, c'est la France encore!» (p. 18) Sul fronte opposto, la letteratura exotique può essere a-coloniale, in mancanza di un altrove corrispondente a un reale possedimento europeo, oppure anticolonialista e, come tale, mette in campo un repertorio tematico che comprende la condanna della civilizzazione e un 
atteggiamento nostalgico per l'integrità oggettiva e morale di quello che appare come un autentico "paradiso perduto".

2 I saggi, alcuni dei quali scritti in collaborazione con altri specialisti e per lo più già apparsi in rivista o in volumi collettanei, sono suddivisi in quattro sezioni. La prima («Littérature coloniale, littérature exotique. Enjeux d'un concubinage littéraire») spazia dall'opera di Pierre Loti a quella di Claude Farrère, di Malraux e di alcuni intellettuali prestati alla letteratura, come Herbert Wild, geologo, autore di romanzi ambientati nell'Indocina francese e in Cina, e Marcel e François Augiéras, rispettivamente zio e nipote, interessati al Maghreb.

3 La seconda («Pierre Loti pierre d'angle et point de bascule») verte su Julien Viaud, in arte Pierre Loti, cui l'A., da specialista, ha dedicato una monografia (Pierre Loti l'incompris, 1986) e il periodico "Revue Pierre Loti», a sua volta antesignano dei successivi «Carnets de l'exotisme» (1980-86). Gli articoli privilegiano la prospettiva biografica: dalle ragioni della scelta dello pseudonimo («Lotiature et temps qui passe», pp. 143-146) ai rapporti con il fratello Gustave (pp. 147-154 e pp. 155-162), il fotografo Joseph Picard (pp. 199-211) e il docente universitario Lafcadio Hearn, traduttore, prima di Henry James, di alcune delle sue opere (pp. 187-197); delle versioni di quest'ultimo viene pubblicata una bibliografia completa nell'«Annexe III» in appendice.

4 La terza parte («Vaillance et défaillances des ailleurs»), oltre a confermare con due saggi la centralità di Pierre Loti nel panorama della letteratura viatoria (Du Nil exotique au "nihil" touristique e De l'identité), dà conto della varietà di opere minori ispirate dall'altrove spaziale e dall'alterità culturale: la Turchia di Hans Christian Andersen, l'Africa francofona di René Caillé, l'America meridionale di Lucien Saignes, il Canada di Xavier Marmier e Gustave Aimard, con l'esclusione però degli autori quebecchesi in ragione dello sviluppo autonomo della letteratura canadese di lingua francese. Al ruolo femminile nel costituirsi del corpus della letteratura viatoria sono poi dedicati due saggi, non coevi e le cui conclusioni non sono univoche: De l'exotisme au féminisme, risalente al 2000, si sofferma sull'apporto teoricamente ipotizzabile da parte delle scrittrici, pervenendo però a un bilancio complessivamente negativo, ovvero la constatazione della mancanza di uno studio sistematico sulle figure di autrici di questo genere letterario e l'esistenza di un unico strumento dove siano repertoriati almeno i nomi delle grandes voyageuses (Dictionnaire illustré des explorateurs français $d u$ XIXe siècle, CTHS, 1992, a firma di Numa Boc, in chiusura del volume Asie); al contrario, il saggio Deux françaises à Constantinople, elaborato sei anni dopo, denota un'inversione di rotta, in quanto si sofferma sui romanzi di Marcelle Tinyare e Hortense-Marie Héliard, alias Marc Hélys, entrambe affascinate dall'odierna Turchia.

Corredano il volume quattro «Annexes» (pp. 397-408), una ricca «Bibliographie» (pp. 409-414) e l'«Index des principaux noms cités» (pp. 415-422). 